\title{
THE ORCHESTRA OF IDEAS: \\ USING MUSIC TO ENHANCE THE 'FUZZY FRONT END' \\ PHASE OF PRODUCT INNOVATION
}

\author{
Mai Khanh Tran* (Corresponding author) \\ University of Birmingham \\ Address: Muirhead Tower, Second floor, College of Social Sciences, University of \\ Birmingham, Edgbaston, Birmingham B15 2TT, United Kingdom. \\ Email: MXT297@,bham.ac.uk
}

Telephone number: $(+44) 7784350475$

Mai Khanh Tran is a PhD student in the Department of Marketing at University of

Birmingham. Her research interests include co-innovation, creativity, aesthetic consumption, arts-based research, and creative methods for research and community engagement.

\section{Christina Goulding}

University of Birmingham

Address: Room 220, Ash House, University of Birmingham, Edgbaston, Birmingham, B15

2TT, United Kingdom.

Email: $\underline{\text { C.Goulding@bham.ac.uk }}$

Christina Goulding is Professor of Marketing at the University of Birmingham. Her research focuses largely on cultural and sub-cultural consumption, 'dark' tourism experiences, the media, place and consumption, and the development of qualitative research methodologies.

\section{Eric Shiu}

University of Birmingham

Address: Room 209, Ash House, University of Birmingham, Edgbaston, Birmingham, B15

2TT, United Kingdom.

Email: e.c.shiu@bham.ac.uk

Eric Shiu is Lecturer in Marketing and Innovation Management at the University of

Birmingham. His research focuses mainly on different aspects of innovation, as well as retail design, relationship quality, and food marketing. 


\begin{abstract}
By introducing music composition theory, we offer a new perspective from which to understand the 'fuzzy front end' (FFE) phase of product innovation with regard to both value outcomes and the innovation process. Focusing on ideas co-created by consumers, we draw on an ethnographic study to examine how young consumers tackled a real-life challenge to produce a digital product that would engage audiences in classical music. Working with two organizations, one a city symphony orchestra, the other a global technology corporation, this work bridges innovation and aesthetics and challenges the established mind-set of the science-art schism in business management. The findings contribute to innovation theory by introducing a hybrid model that structures FFE activities based around the composing process. We also illuminate how music can facilitate and ensure greater value for consumers as 'the composers of ideas'. Managerial implications are suggested.
\end{abstract}

Key words: fuzzy front end, creativity, consumer co-creation, experiential value, aesthetics, music composition. 


\section{The orchestra of ideas:}

\section{Using music to enhance the 'fuzzy front end' phase of product innovation}

\section{Introduction}

The world of the arts and the world of science, and by implication, management science, have predominantly been viewed as opposites. Science, its ontology, methodologies and practices based on hard, cold data derived through 'scientific' means is generally regarded as belonging to the world of objective reason. The arts, on the other hand, are considered to be firmly rooted in the realm of subjectivity, emotions, and aesthetics. Yet this schism, when examined, is not quite so clear cut. For instance, the observational techniques needed to perform modern science came from the skills introduced by Renaissance artists in their attempts to mirror and reproduce nature in its most precise and accurate form (Douglas, 2004). Possibly one of the most celebrated boundary crossers, Leonardo da Vinci, despite producing two of the most famous paintings ever, the Mona Lisa and The Last Supper, was not confined to, or constrained by, the category of artist. On the contrary, he crossed the boundaries of science, art and nature, leaving thousands of pages of observations, sketches and blueprints that have subsequently been examined and studied by physicists, anatomists, botanists, mathematicians and engineers (Bulent, 2004). Despite this, history, and in particular 'Enlightenment' philosophy and the modernist drive towards science, rationality, objectivity and reason, has seen the expulsion of imagination and aesthetics from scientific enquiry (Luhmann, 2000; Daston, 1998). This in turn has resulted in the bifurcation and polarization of science as the arbiter of analysis, and art as the process of synthesis. However, in reality, the scientist and the artist engage in both (Bulent, 2004; Douglas, 1989). As Smith (1970: 493) noted, the study of the interplay between art and science "is not only interesting, but is necessary for suggesting routes out of our present social confusion”. 
Recent shifts in academic thought have sought to challenge such strict binary divisions within the field of management and marketing. This is evident with the emergence of critical schools within the disciplines, cross disciplinary research, the growth of interpretivist approaches and, a growing appreciation and understanding of what the arts can bring to bear on organizational performance at all levels (Darso, 2004). These interdictions may be seen in the spirit of late modernity's increasing tendency towards de-differentiation the erosion of "effacement and elision of established boundaries - high and low culture, education and training, politics and show-business - and the blurring of what were formally clear cult entities (philosophy and literature, author and reader, science and religion etc.)" (Brown, 1995: 197). But to suggest that there is some happy harmonious relationship whereby the arts and the natural sciences are today collaborators working together to determine the most rounded solutions to problems, both academic and practical, would be either misleading or wishful thinking. There are numerous initiatives such as the Welcome Trust's 'Sciart' program which sought to implement C.P Snow's notion of 'Two Cultures' to frame the interaction of artist and scientists as interdisciplinary collaborators (Yang, 2015). However, "communities of scientists and artists put considerable work into maintaining their disciplinary boundaries, and, ironically, so called art-and-science initiatives can be one of the most convenient devices to help accomplish this" (ibid.: 318). Essentially, the 'inter' becomes the illegitimate child of the established disciplines and the results fail to do justice to either disciplines.

The theme of this special issue is how arts can become sources of value creation for business. Drawing on data gathered from ethnographic research involving the innovation process of designing and developing an 'arts meets science' product, we extend this to ask what lessons can business learn from the arts? Our research, unlike many predefined and funded projects, is the result of two independent organizations, one a city symphony 
orchestra, the other a world leading technology corporation, voluntarily coming together to see how, by drawing upon their individual strengths, experience, aesthetic and technological expertise, they could develop a product that would encourage and engage young people in classical music. Critically, they wanted to ensure that the potential users they were aiming to attract were part of the process of innovation and design. Our findings suggest theoretical and methodological implications beyond the immediate context. These include developing new approaches to the notion of value in product innovation; revisiting creative activities in the early stage of idea development; and aiding consumers to leverage their creativity whilst cocreating values with businesses. We focus our discussion on one particular aspect of organizational activity - the fuzzy front end phase in product innovation; and in order to demonstrate our findings, we draw on music composition theory as an alternative framework for understanding the process.

\section{Theoretical development}

\subsection{Fuzzy front end in product innovation}

Since the 1950s, product innovation has been viewed as one of the most vital competencies of an organization (Moustaghfir and Schiuma, 2013). This has become increasingly important in the light of global competition, technological progress, and product complexity (Schiuma et al., 2012). The real key to product innovation success however, lies in the very first stage in which idea generation, idea screening, and concept development take place (Alam, 2006; Reid and de Brentani, 2004). This phase is defined as the 'fuzzy front end' (FFE) since it is characterized by ambiguity and a somewhat chaotic nature (Sanders and Stappers, 2008; Smith and Reinertsen, 1991). Low levels of formalization, unstructured procedures and high levels of uncertainty in FFE require businesses to generate various types of information from both internal and external alliances (Zahay et al., 2004). Recent FFE literature has seen a trend toward involving consumers in the process in order to reduce 
uncertainty in FFE, given that consumers are ultimately the final stakeholder and arbiter of products (Schweitzer, 2014). The role of consumers in FFE can also be found in early research which supported the idea that consumer involvement significantly improved product concepts and offered an effective contribution to developmental activities, including design activities (Harker, 2015; Sanders and Stappers, 2008). Other works focus on the motivation behind consumer engagement (Füller, 2006); issues in managing and facilitating consumers in generating ideas in FFE (Enkel et al., 2005); and consumer competences (Tran, 2017; Hoyer et al., 2010). However, much of this work concentrates on how to attain the most creative ideas from consumers. Conversely, we contend that FFE can be designed to maximize values for consumers as, "innovation is about discovering innovative ways of cocreating value and defining new value propositions" (Mele et al., 2009: 14). This inspired us to re-interpret value creation in FFE where consumers "participate with their own competencies to realize this potential value through the process of value co-creation" (ibid.:16). As innovation is both an outcome and a process in itself (Vargo and Lusch, 2008), we re-examine FFE with regard to both value outcome and the value creation process.

Recent years have seen a radical shift from values as "tangible goods, with a fixed set of features and attributes" towards emotional bonds and the experience of "intangible services and experiences, with high knowledge content" (Romero and Molina, 2011: 452453). Concurrently, the quality of the overall experience in the consumer journey has become the locus of value co-creation rather than traditional product-centric approaches (Prahalad and Ramaswamy, 2004). In the specific context of FFE, creative ideas can be enhanced by incorporating "as much as possible of the flow experience into the various domains" (Csikszentmihalyi, 1996: 10). Consumers participating in FFE can achieve flow experiences under conditions of deep involvement, freedom, self-control, attention, challenge, sense of 
mastery, competence and task enjoyment (Füller, 2006) in creative product concept generation, the key objective in FFE (Im et al., 2013).

The process of generating creative ideas in FFE has become a source of interest for both academics and practitioners (Boeddrich, 2004). Up to now, Amabile's seminal work (1988) is still one of "the most influential creativity theories' from which 'the most commonly used definition of creativity stems" (Shalley and Gilson, 2016: 3-4). The componential theory of creativity (Amabile, 2012) highlights three key components and their interaction in enhancing creativity. First, intrinsic motivation to do the task is positioned as the critical component (Shalley and Gilson, 2016). The second factor relates to domain relevant knowledge and skills, which include personal, educational, technical, and functional background used to generate and integrate knowledge. The last component is the skills in creative thinking, including adopting lenses and combining ways of thinking. Whilst this model has, and continues to have significant influence in creative idea generation, our paper aims to offer a refinement of the model which places greater emphasis, not only on creative idea generation, but also on the importance of experiential values generated from the process.

\subsection{The arts in fuzzy front end study}

In response to the quest for delivering greater consumer experiential values, research supports the value of adopting arts based approaches to assist businesses to identify and build consumer value into new products and services. After all, the arts themselves are experiential and are "consumed primarily for intrinsic rewards - for the experience itself" (Boorsma, 2006: 79). They may be consumed for hedonistic fulfillment, and can be both entertaining and challenging, especially when they involve absorption, engagement, imagination and interpretation (Csikszentmihalyi, 1996). Therefore, when utilizing the arts in the innovation process, there is usually a strong focus on emotional, imaginary, and sensory stimulation in the use of products or services. Indeed, the arts can aestheticize the everyday-life of 
consumers. They can form tastes, transfer these tastes to everyday objects, and influence future product choices (Venkatesh and Meamber, 2008).

Business history reminds us that innovation is often introduced and fostered in the arts (Nissley, 2010). Among the four intersecting levels between the arts and business (Darso, 2004), the highest level in the strategic process is the creative contribution the arts can make in the innovation process (Styhre and Eriksson, 2008). Many innovation projects have even utilized artists for a period of time for the value they can bring with their 'fresh-eyed' approach to organization problems (Taylor and Ladkin, 2009). Essentially, creative individuals can see beyond the horizon of utility and introduce aesthetic skills and qualities (Styhre and Eriksson, 2008). They can also play a central role as co-producers by giving meaning to artifacts.

\subsection{Music and composition theory in the fuzzy front end}

In order to understand the application of arts-based initiatives in our FFE study, we focus our attention on music for its highly emotive nature and its important role in the arts repertoire. During the musical sensory encounter, every sound is associated with feelings which may influence multiple emotions, from melancholy to aggression (Macdonald, 2001). Defined as a higher level of sound with creative patterns, music has been scientifically proven to be "embedded directly in the intellectual dimension of humans' consciousness... [and] generates powerful emotional responses in its listeners" (Radford, 2001: 152).

The music composition process also offers a valid opportunity for examining its potential in mapping the FFE pathway. Composition is "an activity simultaneously of arousal and aesthetic imagining" (Impett, 2009: 408), with relative roles of emotional and intellectual properties (Thagard, 2006). It is this combination of emotion and cognitive thinking in music composition which distinguishes it from the creative process in the innovation literature. When analogous with the FFE process, music making sees these outputs as transitory 
materials that "constitute successive versions of a composition" (Sloboda, 1986: 119). Besides acknowledging evidence of the consciousness of the artists, the music diagram (Figure 1) also highlights the critical role of the unconscious, consisting of knowledge, structures, and skills stored in the long term memory of the composer. From the early stage of establishing a theme to the final manuscript, composition requires the input from general tonal and stylistic knowledge (box F) which can inspire the formulation of the thematic kernel, or help the composers to leave their comfort zone. In addition, the diagram emphasizes the importance of compositional techniques and devices (Box E) that assist transformation and modification of the original theme, and the iterative judgments and modifications that need to be made before a satisfactory final form (box D) is reached. This model still acts as the foundation for recent music composition theories, such as the concept of interspersing stages in the composition process (Newman, 2008).

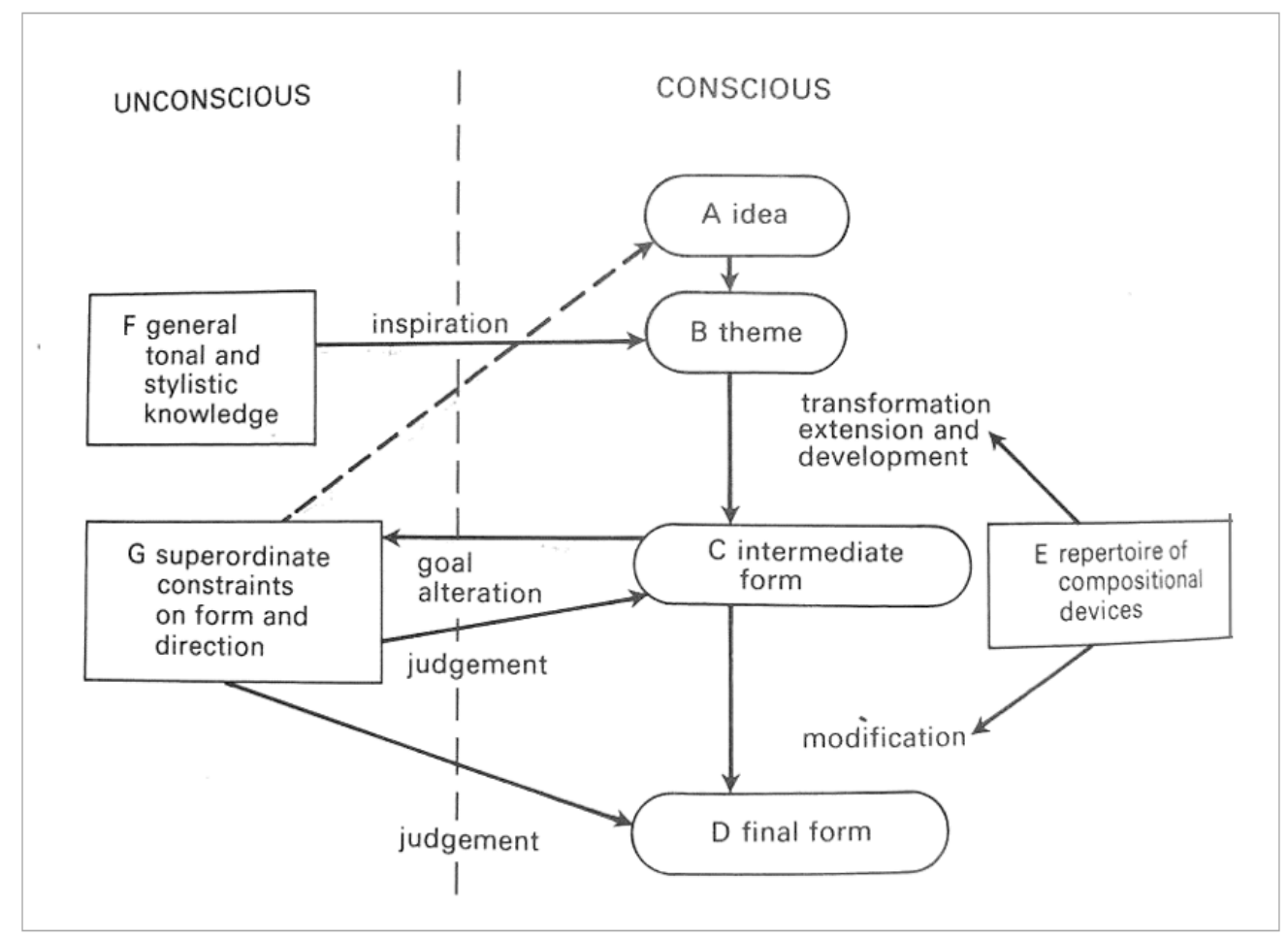

Figure 1: Diagram of typical compositional resources and processes (Sloboda, 1986: 118) 


\section{Methodology}

\subsection{Research questions}

Given the intrinsic value of music and the music composition structured pathway, we contend that the interplay between the arts and technological innovation can offer alternative insights for FFE theory. The paradoxical juxtaposition of opposites can suggest new notions of innovation and, given the context of consumer co-creation, it can offer both functional and experiential values for consumers. This raises the question: how can music enhance the FFE phase in which consumers are involved as developers of ideas? To address this, we posed the following key questions:

1) How can music offer a new approach to value creation in FFE?

2) How can music composition theory suggest the formation of FFE pathways?

3) How can music be used as a stimulus for consumer co-creation in FFE?

\subsection{Research background}

Our research question emerged from the objectives of two renowned organizations - a city classical orchestra and a global technology corporation. The orchestra was founded in 1920, earnt its reputation as one of the world's finest orchestras in 1980, and affirmed its global pre-eminence in 2013. Since then, it has continued to present internationally significant classical seasons to more than 200,000 concert goers annually, and provided around 80,000 opportunities for learning and engagement. The technology corporation is a multinational company with a history of over 100 years. The organization not only offers technology solutions to various industries, it also has a special interest in cross disciplinary collaboration and academic engagement in order to harness a diverse range of knowledge. In 2015, the Director of Learning and Engagement from the symphony orchestra met with an expert from the technology corporation who was also the ambassador of a co-innovation 
scheme in the region. By working together, they aimed to increase young audiences' participation in classical music via technology. One crucial aspect was that young potential users should be integral to the process from start to finish as co-creators of the end product.

Therefore, the university was approached and asked to organize, team lead, and mediate the process over a period of six months. This involved a wide range of activities, from recruiting participants, arranging meeting venues, and offering training courses including project management and design skills. More than 160 applications were submitted for enrolment on the project. As well as the opportunity to work with these companies, a further enticement was the possibility of winning a prize for the best ideas. There were a number of teams working on the project simultaneously, which also introduced a competitive element. Team allocation was done on a random basis, with four young participants, one academic lead and one adviser. Taking on this advisory role, the lead author worked closely with all members and engaged in the process from the start. Furthermore, a conductor was invited to join the project to inspire the students with his repertoire of knowledge and skills in music and performance, real stories, and aesthetic experiences.

\subsection{Research design and process}

To make sense of the creativity process and to recognize both issues and opportunities arising from the marriage of music and technology, we adopted an ethnographic approach to data collection whereby one author was immersed in all aspects of the research over the sixmonth duration of the project. Ethnography, by its nature enables the researcher to capture the different ways that actors construct and experience their social realities through a deep immersion in their world (Denzin and Lincoln, 2000; Schwandt, 1999). Moreover, we acknowledge that all members are active participants in the construction of multiple realities, and, that the social, cultural and organizational worlds in which they are embedded, shape and give meaning to these constructions (Brewer, 2000; Guba and Lincoln, 1994). 
Data collection included participant observation as a prime source of information. The author was in charge of assisting students' activities, advising and sharing knowledge with them, and verifying their work. This generated field notes and memos (Glaser and Strauss, 1968) regarding participants' progress, key events, and milestones in their creative process. Data were also collected in the form of informal conversation, semi-structured interviews with participants at the various stages of the project, and a written report in the form of student's reflective diaries. The format was kept relatively flexible to maximize space for students to demonstrate their ideas without leading questions. Hence, each of them would focus on a different angle in their learning diary, which afforded opportunities to make sense of individual experiences and gain a holistic view of the innovation process from distinct viewpoints.

A netnographic approach was also conducted to identify and explore the team's behaviors in their virtual context. Netnography (O’Sullivan, 2016; Kozinets, 2002) aims to analyze the free behavior of individuals on the Internet in order to understand "their attitudes, perceptions, imagery, and feelings" (Langer and Beckman, 2005: 192). As such, it generates "thick description of the lived experience of participants" (Elliott and Elliott, 2003: 215). Netnography was particularly suitable as participants were 'screenagers' - teenagers born in the age of multi-screens with an affinity with electronic communication such as computers and mobile phones (Tapscott, 2008; Radford and Connaway, 2007). With the informed consent of participants, we captured all the details and the development of ideas as expressed and communicated through various channels. In this project, these main online channels included Facebook, Pinterest, email, and a CANVAS platform hosted by the university. As their adviser, the author was invited to join all the groups and take part in discussions. This offered the opportunity to access a wide range of data including texts, videos, images, mockups, sketches, and working prototypes that were shared among team members. 


\subsection{Data analysis}

Data were analyzed through an iterative process of data collection, simultaneous analysis and the search for patterns and themes (Glaser and Strauss, 1968). Initially, we applied a descriptive interpretation of data through open coding, and eventually moved through a series of analytical abstractions by constantly comparing data in order to identify more conceptually significant themes that had a relationship to each other. This resulted in the development of a framework based on four key stages in music composition: germinal idea, theme, intermediate forms, and final form (Sloboda, 1986).

\section{Presentation of data and findings}

\subsection{Stage 1: Germinal idea}

In the early stage of the project, participants experienced ambiguity and confusion regarding the process of generating new ideas or even thinking creatively about the ultimate deliverable output. "Their first real breakthrough came when the connection with music was made instead of an extensive amount of research" (Field notes).

\subsubsection{Constraints to creativity}

The first three months were spent on developing participants' knowledge of innovation, creativity, and group work before entering the period of tackling the challenge in earnest. The two representatives from both companies were invited to join the training days to suggest the exploration of interesting topics to inspire ideas. For example, the role of technology in improving people's lives and the arts in supporting education and community engagement. These preparatory activities resulted in ideas ranging from a device that could turn all types of music into classical music, to road show exhibitions, to a machine selling fluffy dinosaurs for children attending concerts. However, the team failed to come up with a concrete idea for several reasons. First, their lack of knowledge of technology in the context 
of the arts made them hesitant when evaluating other member's proposals, resulting in fragmented and premature ideas. Second, they lacked confidence in their knowledge of classical music which was perceived as "posh, middle aged and middle class" (Male participant 1). Third, there was a "fear of being in the spotlight" (Female participant 1) during face-to-face interactions, and avoidance of speaking out in discussion. This sometimes caused a break-down in communication resulting in blocks in creativity. It also imposed a heavier workload when dealing with deadlines, as one of the participants noted:

"One of the key criticisms which I could make of our team as whole... is that we could have met earlier in the procedure... It would have given us extra time in the earlier stages and helped us move quicker from simply thinking of the ideas to developing the presentation of that idea..." (Male participant 2)

\subsubsection{Music as the trigger and inspiration}

Recognizing that participants might not absorb the huge repertoire of knowledge and skills during their training days and that their biggest challenge was to break the silence in their meetings, the author tried a different method with the expectation that this could change their mood and inspire their thinking. This involved the introduction of classical music. "The team started listening to classical music in different contexts, from concerts to movies, retailing stores, and advertisements... They recognized that they were much more exposed to classical music, even subconsciously, than they had ever imagined" (Field notes). Music also stirred their emotions, from feeling inspired and energetic to feeling calm and relaxed. From their experiences and a new emotional connection to classical music, it became clear that any creative innovation should be rooted in the experience itself:

"...gaining first-hand experiences is also another way to enhance competences. From our situation, listening to the live orchestral concert brought different sensations which were helpful for the project and made it progress" (Female participant 2). 
The team began to think of possible options for digital products which could contain recorded music to assist users by influencing their mood to inspire them in their daily lives. Drawing on secondary market research sources the team chose teenagers as the target users of the product since they, as young adults, could add their own insights and experiences to the product's development. Further research corroborated their decision to develop a mobile app as "it was one of the most widely used form[s] of technology by young audiences" (Male participant 2). Moreover, since the symphony orchestra did not have a mobile app, their idea would not clash with its existing channels.

\subsubsection{Summary}

The idea of co-creation has generated a wealth of literature within marketing and innovation management (Franke and Shah, 2003). Yet, despite calls for greater, mutual consumer/organization participation in the creative process, less attention has been paid to the process of consumer engagement (Brodie et al., 2013). Moreover, and drawing on the analogy of the composer, musicians have to learn their trade, which not only involves technical and artistic skills, but also the development of creative skills. No composer simply produces a score without undergoing a journey of discovery, starting with the initial idea (Lapidaki, 2007). Similarly, no musician picks up an instrument for the first time and magically plays with dexterity. Consumers, no matter how market savvy, cannot engage fully in the creative process without some form of integration into the company/organization (Vargo, 2008). They may need training in specialist areas as well as time and support to explore, nurture, and express ideas through the most effective form of communication (Cova and Salle, 2008). Vital to the process of group creativity is the identification of a trigger that bonds the group together and acts as a source of inspiration. In this case it was classical music which was aligned with the project objectives. It did, however, involve a separate process of inculcation into classical music, its forms and its meanings. 


\subsection{Stage 2: Theme}

After the germinal idea, the next stage was to assess the viability of the idea and specify the functions and design of the product. At this stage, “...both knowledge and tools are required to tease out the theme... This signaled the quest for transferring, expressing, and exchanging ideas beyond the group" (Field notes). It also introduced the notion of the instrument, and in particular, the importance of fine tuning.

\subsubsection{Inspiration as knowledge}

The second stage continued to stress the importance of inspiration in polishing ideas and identifying a clear direction in product development. Inspiration was rooted in personal interests, life experiences, the people they talked to, and incidents that they had been through. "They based their ideas on the real contexts that were most familiar to them as teenagers and exploratory research in order to shortlist theme options: a music revision app, an exercise app and a language revision app" (Field notes).

\subsubsection{The 'instrument' in idea composition}

Since each theme would lead to different functions, content, and interfaces of the mobile app, participants decided to test their ideas and design on a sample of their intended audience. The team used Pinterest, a social media platform which teenagers are familiar with, as the visual discovery tool to find, store, present, and exchange ideas. They generated images of music mobile apps from the Internet as examples, which they then inserted into a survey. This platform allowed the team to collect feedback from respondents since they could search and 'pin' images they liked on their Pinterest board (Figure 2). Their findings showed that "students expected to have a music app that could help them when revising - by helping them to relax and concentrate while studying" (Female participant 2). Also, from these pinned images, it was decided that the app should follow a bright, neat, and clean style of design. 


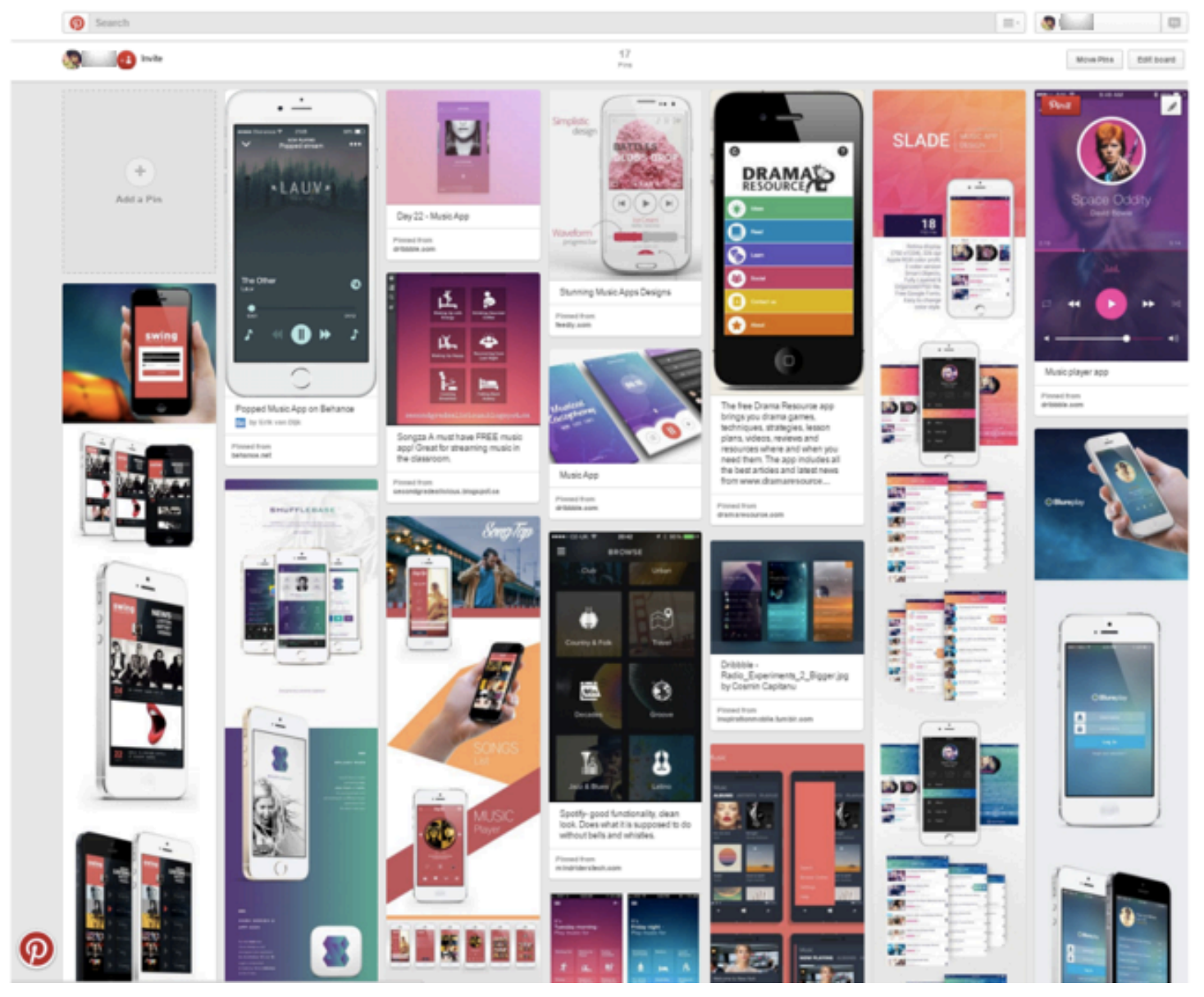

Figure2: A Pinterest board from the study

\subsubsection{Summary}

This stage signalled a transition in the role of team members, from participants to active composers of ideas. Inspiration, became the source of knowledge and drove the way the team generated information and explored possible ideas - an important activity in the innovation literature.

However, the task of transferring and making sense of knowledge in the fuzzy stage is a real challenge. It is especially challenging when information needs to be exchanged among people from different domains and with different skills which have to be coordinated for a creative solution. Thus, a quest for a supporting tool to generate and exchange ideas commenced (Amabile, 2012). This issue can also be found in composition theory. A musical instrument is commonly found in exploring the basic question of how the performer conveys 
his/her ideas to the listeners (Roger and Edward, 1990). Just as composers need to play their first piece of music for reflection, inspiration, and refinement, participants in our case chose Pinterest as their instrument to mediate their interactions, store their ideas, as well as exchange and generate new knowledge for creative solutions. Introducing and utilizing an instrument in the early stages of the idea development process proved to be helpful for the team in tackling the challenge of communication with people from different backgrounds, especially when the idea still lacked structure.

\subsection{Stage 3: Intermediate forms}

While creating intermediate forms, participants encountered limitations in their design skills. This block, however, forced them to find further instruments to transform their mind sketches into visible designs which assisted both their idea composition and their presentation. This stage also saw "a transition in their feelings and experiences from anxiety to arousal... Participants started to enjoy challenging their limits through learning and gaining new skills" (Field notes).

\subsubsection{The first sketch equipped by instrument}

Findings from the survey and evaluation from both technology and music specialists helped the team confirm their idea and specify the product function to illuminate the theme through a design sketch. However, limited skills and competence in graphic design brought a further challenge - that of transforming the findings of the survey into real work:

"Heading further into the project ... we hit a hit of a brick wall as none of us had ever done any graphic design before and consequently had no experience." (Male participant 1)

The team joined a training workshop provided by the innovation project and started creatively experimenting with designs on Photoshop. Being new to this instrument took time 
when transferring ideas into a visible format, especially when deciding the color and early features of the app.

\subsubsection{The second sketch inspired by stylistic knowledge}

They soon recognized that being able to use software or tools did not mean they were able to design. To gain inspiration for design development, the team decided to present their ideas and their first sketch to the orchestra's representative. At this stage, the perceived boundary between novices and experts in classical music started to blur. Their hesitance was replaced by eagerness at the challenge of co-developing ideas:

"I believe that we learnt from this experience at our meeting...We felt far more mature and comfortable, what's more we felt more confident in asking questions" (Female participant 1)

With an interest in the idea and high expectations of the feasibility and value of the app, the representative shared branding advice, motivating the team and providing suggestions for design style. As a result, they started to explore further mobile apps for young audiences through various case studies, mock-ups, and sample sketches shared by their adviser in order to develop their work in a more professional manner.

\subsubsection{The third sketch as a working prototype}

Aiming high, they decided to use a platform that could turn sketches into working prototypes called 'Popapp', an app devised by Google. This platform allowed them to "produce a smart, professional looking, interactive storyboard for the app" (Male participant 2). This involved real movements of interfaces after every click on the functional button which made knowledge transformation easier through the use of visual aids and virtual interaction. 


\subsubsection{Summary}

In music composition theory, the intermediate forms play a crucial role in editing and refining the creative process (Robinson et al., 2011) and, is thought to be the outcome of the composition process, together with the final deliverable product (Polfreman, 1999). Similarly, we found that the team made progressive developments through continuously editing and refining sketches in order to turn their theme into the final product (Figure 3).

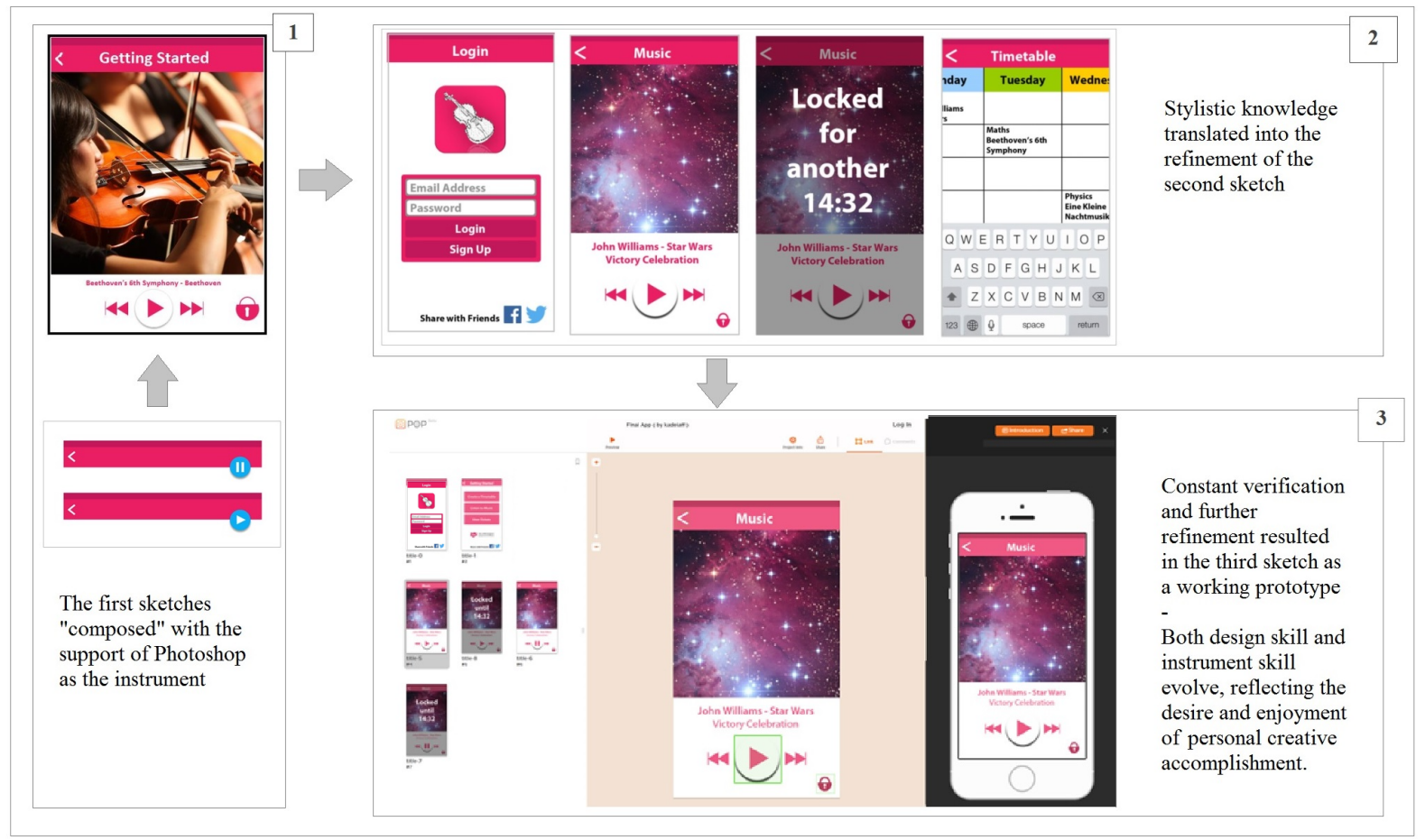

Figure 3: The development of intermediary forms (Extracted from the Facebook group, Popapp page, and Field notes)

The quality of their sketches was improved through the assistance of further instruments. Although it is less common to think of the instruments that composers use, the stipulation of which and how instruments are used is an important part of the skill set of the composer (Alperson, 2008). Just as composers usually use a repertoire of compositional devices for different purposes, (Sloboda et al., 2009), participants in our case chose various instruments to accomplish their allocated tasks. It is worth mentioning that, during this stage, the team's attempts to use unconventional techniques to assist their idea performance proved 
to be both enjoyable and delivered a sense of personal creative accomplishment. Participants showed that they increasingly took control of the process. They found the challenge more manageable together with continuously finding, gaining, and mastering required skills to tackle it. This set the foundation for them to gradually achieve a flow experience - the optimal experience which occurs when both challenges and skills reach their climax (Csikszentmihalyi, 1996).

\subsection{Stage 4: Final form}

"Before arriving at the final output, radical change can still take place through reflection and further knowledge from specialists" (Field notes). During this stage, the mindset of the composer stimulated the participants to take ownership of the art making process. The team 'played through' their idea composition through strict rehearsal and practice. The true reward of their effort and creativity was also revealed on their presentation day.

\subsubsection{Radical improvement through the adoption of a musical mind}

As the presentation day approached, participants were given the opportunity to watch a conductor perform on stage. This inspired the team and gave them a sense of performance and presentation. As the conductor described:

"In a physical performance, you will see the conductor coming on the stage, the orchestra standing, the audience applauding ... and a special silence before the music begins. All this generates a sort of expectation and excitement among the audience ... what we are here for, what we are going to listen to, what is going to happen here...You have a true theophany effect." (The conductor)

His thoughts encouraged the team to prepare an 'idea performance' with the use of sense-evoking techniques to evoke expectation, excitement and a 'theophany effect' for their audience. With their own experience of how music might trigger interest and create a social bond among people, they conducted intensive research on short pieces of classical music to include in their opening. 
The conversation also helped them to widen their repertoire of music. Motivated by the conductor's creativity and the ability to immerse himself in the perfection of his art, the team ran through all of their outputs, striving to elevate them to an art form. In their final review, they invested heavily in the design and branding of the app, improving in the process some interfaces (Figure 4). This was done to "create a good hook" and "highlight and expand the core value [of their app]" (Male participant 2). They also continued to explore another new instrument - the use of Prezi to replace the conventional PowerPoint as they wished to "encourage better interaction and [offer] a more eye-appealing interface with the audiences" (Male participant 1). The final product, or the 'end of the composition', was the result of gradual improvements, honed through a sequence of sketches as a core part of the production of ideas (Bennett, 1976).

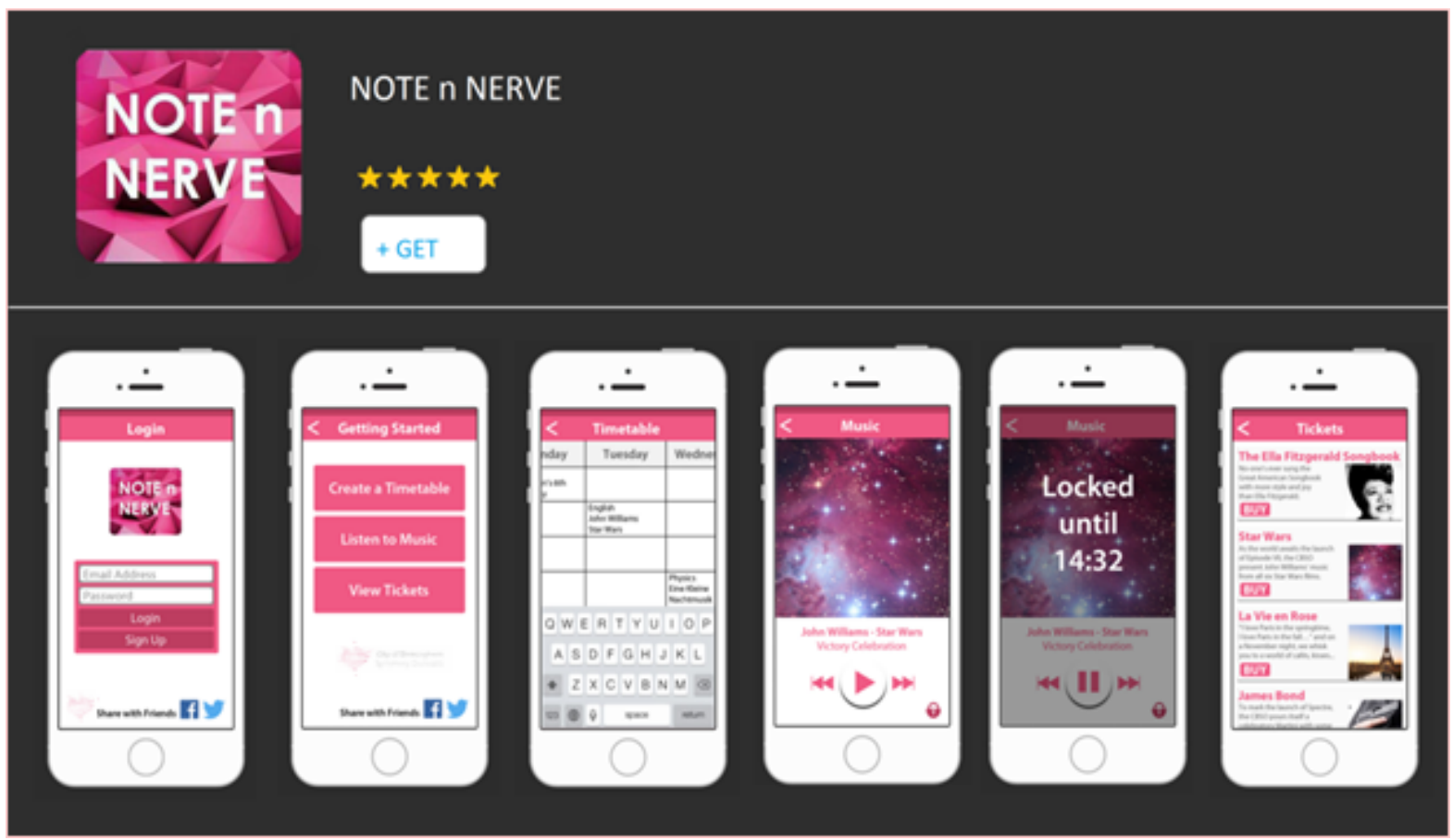

Figure 4: Final form of the mobile app (Logo of the symphony orchestra has been blurred)

\subsubsection{Show time}

On presentation day, their use of a short orchestral symphony in the opening section of their presentation created a positive aesthetic impression in front of more than one hundred guests and judges. It was deemed to be "extremely engaging... an unexpected and pleasant 
surprise" (Judging board). Their idea was also judged to be "a brilliant combination of both arts and science". Their efforts did not go unrewarded as they were offered a sponsorship to fully develop the app based on the production of a more detailed plan.

\subsubsection{Summary}

The twist in the last stage occurred when participants started to adopt the mind-set of the composer in art making and art consumption. In aesthetic activities, including music, this concept is especially appropriate when consumers seek aesthetic fulfillment through absorption, engagement, imagination and the interpretation of music and other forms of consumption that elevate the individual beyond the level of everyday experiences (MacDonald et al., 2006). In this case, a flow experience arose when the team, confidently, perceived their product as an art work, which they were proud to present in front of an audience.

\section{Contributions and conclusion}

\subsection{Values as product and process}

Many high-impact science and innovations are found to be grounded in unconventional combinations, especially when they relate to the arts (Bakhshi et al., 2008). In our case study, the marriage of science/technology and the arts resulted in an emotionoriented technological product that was aimed at enhancing feelings of wellbeing. It is currently being developed with a strong focus on experiential value and emotion fulfillment. This makes it distinct from other digital products in the market place which are positioned as radical high-technological innovations or cost saving channels (Crawford et al., 2012).

In addition to the technological output, the whole FFE process brings to light the experiential aspect of value creation. It highlights the formalization of active consumer engagement in the development of a new arts-based product by tracing creative activities 
through a number of prescriptive 'compositional' stages. Various experiences can be achieved and transformation can occur in a staged sequence in which people move from apathy, worry, and anxiety at the beginning of a challenge, toward arousal and ultimately a 'flow' experience that concerns "conscious effort and the direction of psychic energy to produce a feeling of wellbeing" (Goulding, 2000: 270). Importantly, our study showed that only when the integration of music and technology took place, could participants start to generate a flow experience.

\subsection{The fuzzy front end as an idea composition process}

The orchestration of multiple factors, actors and instruments in FFE can be summarized in a hybrid model based on the integration of music composition and creativity theory (Figure 5). This opens up opportunities for firms to further engage with their consumers through experiences, values, and favourable connections. It also supports us in proposing a list of activities to suggest how firms can 'stage experiences' (Pine and Gilmore, 1999) for their consumers during the project.

When re-developed with a musical mind, the FFE process takes into consideration the unconscious aspect of participants' creativity by recalling their prior knowledge and experiences and gaining new ones. This acquired knowledge and skills are integral to the development of personal life experiences, which can build up participant's long-term knowledge and be applied to new compositional problems (Sloboda, 1986). Whilst this strongly supports the creation of the final outcome, it also enhances personal values for participants, which leads to higher commitment, autonomy, and motivation. The hybrid model further highlights the importance of the instrument and, more specifically, the process of instrumentalization (Gall and Breeze, 2005). This process occurs when "the instrument does not exist in itself but becomes an instrument when the person using it has been able to appropriate it for themselves and has integrated it with their activity" (Verillon and Rabardel, 
1995: 80). Once consumers are empowered as designers/co-designers, firms need to consider which types of instruments and tools are convenient and familiar to consumers, how they can transform them by taking them in unplanned directions, and how skills emerge, extend, and develop as part of creation (Sloboda, 1986).

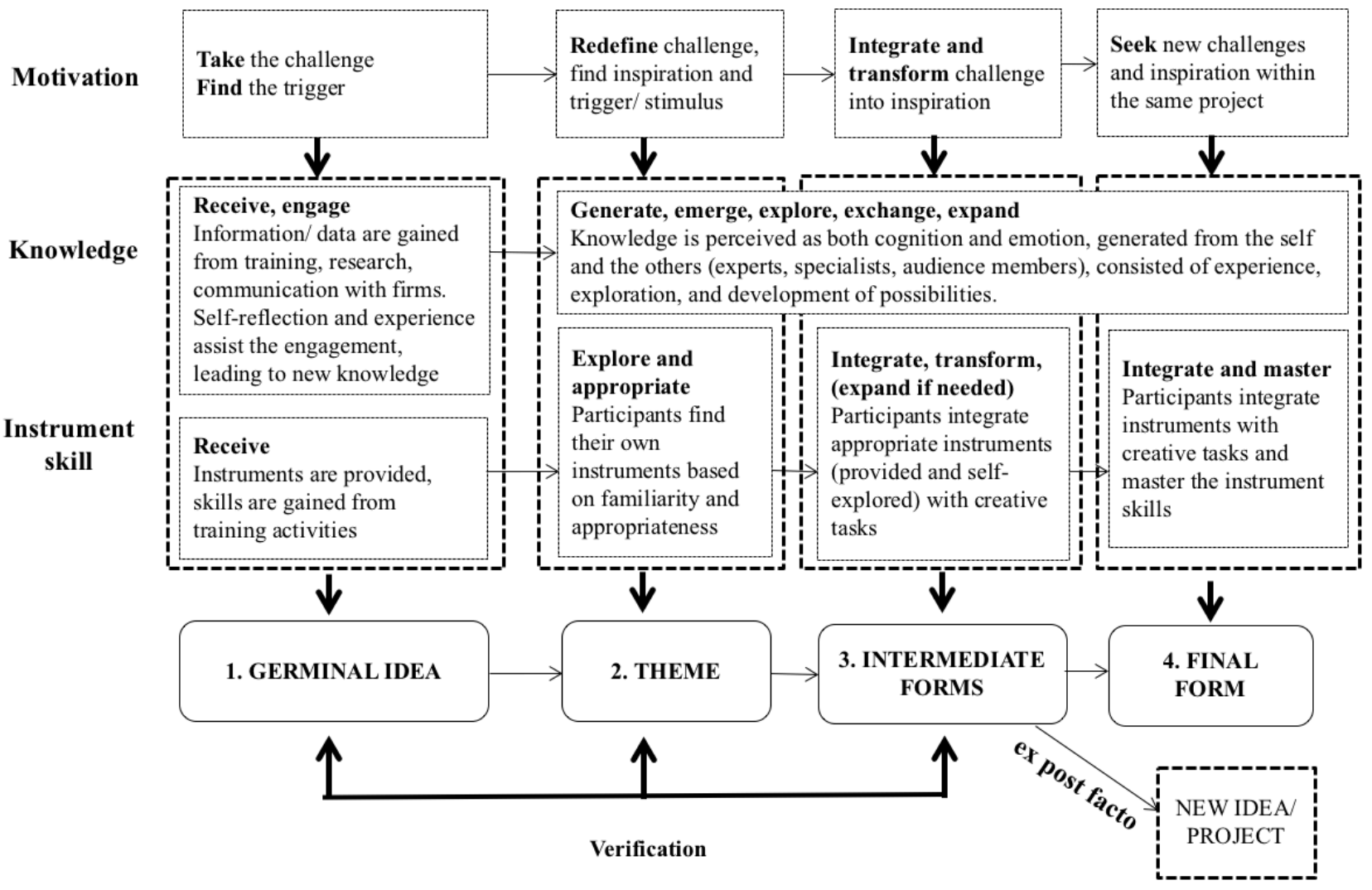

Figure 5: Hybrid model of FFE activities

Our model also adds a further element entitled 'ex-post facto' to highlight the alternative views of creative work in different contexts, time, and space. Art history reveals that many cultural works such as those by Bach, the first of the Great German composers in the tonal tradition, were not fully recognized during their lifetime (McClary, 1987). Therefore, storing art works and tracing back the art-making process through sketches can be insightful, as they are "signs of competence, necessary and enabling resources for the compositional process" (Sloboda, 1986: 104). In music composition, postulating basic compositional techniques from sketches or the reproduction of sketches from the melodic fragments, need to be examined in order to understand the composition. Full notes in time 
sequence should be kept and recorded to reflect and facilitate the development of further sketches to allow for later modification, completion, and maturity of idea - or a completely new musical work.

\subsection{Music as stimulus in fuzzy front end}

When re-examining the idea orchestration in FFE, we found that important twists and turns throughout the project usually involved music. This allows us to contend that music and music-related experience can aid consumer co-creation in FFE. In our case, the initial trigger was classical music, which is also the core offering of the symphony orchestra. It was introduced to participants to inspire their association with music in their own life events, which allowed them to express their needs and problems in the most natural context. Further triggers related to music, including discussion with representative and specialists, were staged along the project to continuously inspire ideas. With evidence of a powerful aid in creativity, our paper suggests music is an important form of art that can assist individuals and groups to tackle mental blocks, alongside imagery and visual thinking as commonly found in extant research (Verstijnen et al., 1998).

\subsection{Managerial implications}

In our study, the question of a technological product that engaged audiences in classical music was addressed by the creation of a mobile application. However, the full response to the challenge was the act of empowering consumers to collaborate with the firms, which then brought them closer to classical music and let them immerse themselves into various types of experiences: "the consumer lives these intense moments of immersion through a complex combination of nesting, investigating and stamping operations in which one conjures up all of one's competencies and knowledge" (Carù and Cova, 2006: 11). This type of co-creative project can, therefore, be adopted outside of the arts sector by businesses that aim to actively communicate with [young] audiences. Innovation projects should, 
therefore, be seen as the starting point of a conversation, the establishment and maintenance of a relationship, and a communication channel established and developed actively by both sides (Gummerus, 2013).

\subsection{Avenues for future research}

Whilst our ethnographic research has limitations linked to the context and empirical case of the study, it opens up avenues for future research. Music has often been overlooked (Belfiore and Bennett, 2007) despite scientific findings which show that we are a "musical species", and "to be human is to be musical" (Mithen, 2009: 3-4). The functional niche that music is part of (Sloboda et al., 2009) can be further explored, allowing many opportunities for creating music-based products to engage consumers. The long tradition of music in the humanities can extend the potential of the application of music to business, and illustrate, for example, how music supports the creation of social bonds in group creativity (Huron, 2001), or how it provides a sense of group identity and develops a personal understanding of self (Mithen, 2009). Moreover, other art forms can be examined in product innovation to confirm whether they can make similar contributions. With the emergence of theories from our study, we suggest more empirical research on arts-based initiatives in developing theories of product design innovation (Shiu, 2017) and experience innovation, including space and environment (Prahalad and Ramaswamy, 2004). 


\section{Reference list}

Alam, I. (2006). Removing the fuzziness from the fuzzy front-end of service innovations through customer interactions. Industrial Marketing Management, 35 (4), 468480 .

Alperson, P. (2008). The instrumentality of music. The Journal of Aesthetics and Art Criticism, 66 (1), 37-51.

Amabile, T. (2012). Componential theory of creativity. Boston, MA: Harvard Business School.

Amabile, T. M. (1988). A model of creativity and innovation in organizations. Research in organizational behavior, 10 (1), 123-167.

Bakhshi, H., Schneider, P., \& Walker, C. (2008). Arts and humanities research and innovation. Arts and Humanities Research Council (AHRC) \& NESTA, Bristol \& London.

Belfiore, E., \& Bennett, O. (2007). Rethinking the social impact of arts, a historical review. International Journal of Cultural Policy, 13, 135-151.

Bennett, S. (1976). The process of musical creation: Interviews with eight composers. Journal of research in music education, 24 (1), 3-13.

Boeddrich, H. J. (2004). Ideas in the workplace: a new approach towards organizing the fuzzy front end of the innovation process. Creativity and innovation management, 13 (4), 274-285.

Boorsma, M. (2006). A strategic logic for arts marketing: Integrating customer value and artistic objectives. International Journal of Cultural Policy, 12 (1), 73-92.

Brewer, J. (2000). Ethnography. McGraw-Hill Education (UK).

Brodie, R. J., Ilic, A., Juric, B., \& Hollebeek, L. (2013). Consumer engagement in a virtual brand community: An exploratory analysis. Journal of Business Research, 66 (1), 105-114.

Brown, S. (1995). Postmodern marketing. London: International Thompson Business Press.

Bulent, A. (2004). Math and the Mona Lisa: The art and science of Leonardo de Vinci, New York: Smithsonian Institute.

Carù, A., \& Cova, B. (2006). How to facilitate immersion in a consumption experience: Appropriation operations and service elements. Journal of Consumer Behaviour, $5(1), 4-14$. 
Cova, B., \& Salle, R. (2008). Marketing solutions in accordance with the SD logic: Co-creating value with customer network actors. Industrial marketing management, 37 (3), 270-277.

Crawford, G, Gosling, VK, Bagnall, G \& Light, BA. (2012). Pulse: The London symphony orchestra students mobile project, Project Report, NESTA, London.

Csikszentmihalyi, M. (1996). Flow and the psychology of discovery and invention. New York: Harper Collins.

Darso, L. (2004). Learning Tales of Arts-in-Business. Samfundsliteratur, Denmark.

Daston, L. (1998). Fear and Loathing of the imagination in science. Science in Culture, 127 (1), 73-95.

Denzin, N. K., \& Lincoln, Y. S. (2000). The discipline and practice of qualitative research. Handbook of qualitative research, 2, 1-28.

Douglas, K. (ed.) (2004). The New Left and the 1960s: Collected Papers of Herbert Marcuse, (3). Routledge.

Douglas, P. (1989). Modernism and Science: The Case of Pound's ABC of Reading. Paideuma, 18, 187-196.

Elliott, R., \& Jankel-Elliott, N. (2003). Using ethnography in strategic consumer research. Qualitative market research: An international journal, 6 (4), 215-223.

Enkel, E., Kausch, C., \& Gassmann, O. (2005). Managing the risk of customer integration. European Management Journal, 23 (2), 203-213.

Franke, N., \& Shah, S. (2003). How Communities Support Innovative Activities: An Exploration of Assistance and Sharing Among End-Users. Research policy, 32 (1), 157-178.

Füller, J. (2006). Why consumers engage in virtual new product developments initiated by producers. NA-Advances in Consumer Research, 33.

Gall, M., \& Breeze, N. (2005). Music composition lessons: the multimodal affordances of technology. Educational Review, 57 (4), 415-433.

Glaser, B. G., Strauss, A. L., \& Strutzel, E. (1968). The Discovery of Grounded Theory; Strategies for Qualitative Research. Nursing Research, 17 (4), 364.

Goulding, C. (2000). The museum environment and the visitor experience. European Journal of marketing, 34 (3/4), 261-278.

Guba, E. G., \& Lincoln, Y. S. (1994). Competing paradigms in qualitative research. Handbook of qualitative research, 2 (163-194), 105.

Gummerus, J. (2013). Value creation processes and value outcomes in marketing theory: strangers or siblings?. Marketing Theory, 13 (1), 19-46. 
Harker, L. (2015). Exploring the Role of the Customer in the Fuzzy Front End of Innovation.

Hoyer, W. D., Chandy, R., Dorotic, M., Krafft, M., \& Singh, S. S. (2010). Consumer co-creation in new product development. Journal of Service Research, 13 (3), 283-296.

Huron, D. (2001). Is music an evolutionary adaptation? Annals of the New York Academy of sciences, 930 (1), 43-61.

Im, S., M. M. Montoya, and J. P. Workman (2013). Antecedents and consequences of creativity in product innovation teams. Journal of Product Innovation Management, 30 (1), $170-85$.

Impett, J. (2009). Making a mark: the psychology of composition. Oxford handbook of music psychology, 403-412.

Kozinets, R. V. (2002). The field behind the screen: using netnography for marketing research in online communities. Journal of marketing research, 39 (1), 61-72.

Langer, R., \& Beckman, S. C. (2005). Sensitive research topics: netnography revisited. Qualitative Market Research: An International Journal, 8 (2), 189-203.

Lapidaki, E. (2007). Learning from masters of music creativity: Shaping compositional experiences in music education. Philosophy of Music Education Review, 15 (2), 93-117.

Luhmann, N. (2000). Art as a social system. Stanford University Press.

MacDonald, A. S. (2001). Aesthetic intelligence: optimizing user-centred design. Journal of Engineering Design, 12 (1), 37-45.

MacDonald, R., Byrne, C., \& Carlton, L. (2006). Creativity and flow in musical composition: An empirical investigation. Psychology of Music, 34 (3), 292-306.

McClary, S. (1987). The Blasphemy of Talking Politics during Bach Year. In Music and Society: The Politics of Composition, Performance, and Reception, edited by Richard Leppert and Susan McClary, 13-62. Cambridge and New York: Cambridge University Press.

Mele, C., Colurcio, M., \& Russo Spena, T. (2009). Alternative logics for innovation: a call for service innovation research. In Proceedings of the naples forum on services conference.

Mithen, S. (2009). The music instinct. Annals of the New York Academy of Sciences, 1169 (1), 3-12.

Moustaghfir, K., and Schiuma, G. (2013). Knowledge, learning, and innovation: research and perspectives. Journal of knowledge management, 17 (4), 495-510. 
Newman, T. U. (2008), The creative process of music composition: A qualitative selfstudy. New York University.

Nissley, N. (2010). Arts-based learning at work: economic downturns, innovation upturns, and the eminent practicality of arts in business. Journal of Business Strategy, 31 (4), 8-20.

O'Sullivan, S. R. (2016). The branded carnival: the dark magic of consumer excitement. Journal of Marketing Management, 1- 26.

Pine, B. J., \& Gilmore, J. H. (1999). The experience economy: work is theatre \& every business a stage. Harvard Business Press.

Polfreman, R. (1999). A task analysis of music composition and its application to the development of Modalyser. Organised Sound, 4 (1), 31-43.

Prahalad, C. K., \& Ramaswamy, V. (2004). Co-creation experiences: The next practice in value creation. Journal of interactive marketing, 18 (3), 5-14.

Radford, M. (2001), Aesthetic and religious awareness among pupils: similarities and differences. British Journal of Music Education, 18 (2), 151-159.

Radford, M. L., \& Connaway, L. S. (2007). Screenagers and live chat reference: Living up to the promise. Scan, 26 (1), 31-39.

Reid, S. E., and U. De Brentani. (2004). The fuzzy front end of new product development for discontinuous innovations: A theoretical model. Journal of Product Innovation Management. 21 (3), 170-84.

Robinson, N. G., Bell, C. L., \& Pogonowski, L. (2011). The Creative Music Strategy A Seven-Step Instructional Model. Music Educators Journal, 97 (3), 50-55.

Roger A. Kendall and Edward C. Carterette (1990). The Communication of Musical Expression, Music Perception: An Interdisciplinary Journal, 8 (2), 129-163.

Romero, D., \& Molina, A. (2011). Collaborative networked organisations and customer communities: value co-creation and co-innovation in the networking era. Production Planning \& Control, 22 (5-6), 447-472.

Sanders, Elizabeth B.-N, and Pieter Jan Stappers. (2008). Co-creation and the New Landscapes of Design. CoDesign, 1-16.

Schiuma, G., Carlucci.D, Lerro,A. (2012). Managing knowledge processes for value creation, VINE, 42 (1), $4-14$.

Schwandt, T. A. (1999). On understanding understanding. Qualitative inquiry, 5 (4), 451-464. 
Schweitzer, F. (2014). Integrating customers at the front end of innovation. In Management of the fuzzy front end of innovation (pp. 31-48). Springer International Publishing.

Shalley, C. E., \& Gilson, L. L. (2016). Creativity and the management of technology: Balancing creativity and standardization. Production and Operations Management.

Shiu, E. (Ed.). (2017). Research Handbook of Innovation and Creativity for Marketing Management. Edward Elgar Publishing.

Sloboda, J. A., Lamont, A., \& Greasley, A. (2009). Choosing to hear music. Oxford handbook of music psychology, 431-40.

Sloboda, John A. (1986). The Musical Mind: The Cognitive Psychology of Music. Oxford Psychology Series.

Smith, S. (1970). Art, technology and science: Notes on their historical interaction. Technology and Culture, 11 (4), 493-549.

Smith, P. G., \& Reinertsen, D. G. (1991). Developing new products in half the time.

Styhre, A., \& Eriksson, M. (2008). Bring in the arts and get the creativity for free: A study of the Artists in Residence project. Creativity and Innovation Management, 17 (1), 47 57.

Tapscott, D. (2008). Grown Up Digital: How the Net Generation is Changing Your World HC. McGraw-Hill.

Taylor, S, \& Ladkin, D. (2009). Understanding Arts-based Methods in Managerial Development. Academy of Management Learning \& Education. 8 (1), 55-69.

Thagard, P. (2006). Hot thought. Mechanisms and Application of Emotional Cognition. Bradford Book: Cambridge, MA-London, 34.

Tran, M. K. (2017). Four decades of engaging customers in product innovation. In Shiu, E. (Ed.) Research Handbook of Innovation and Creativity for Marketing Management, $91-121$.

Vargo, S. L. (2008). Customer integration and value creation Paradigmatic Traps and Perspectives. Journal of service research, 11 (2), 211-215.

Vargo, S. L., \& Lusch, R. F. (2008). Service-dominant logic: continuing the evolution. Journal of the Academy of marketing Science, 36 (1), 1-10.

Venkatesh, A., \& Meamber, L. A. (2008). The aesthetics of consumption and the consumer as an aesthetic subject. Consumption, Markets and Culture, 11 (1), 45-70. 
Verillon, P. \& Rabardel, P. (1995). Cognition and artefacts: A contribution to the study of thought in relation to instrument activity, European Journal of Psychology in Education, 10 (1), 77-101.

Verstijnen, I. M., van Leeuwen, C., Goldschmidt, G., Hamel, R., \& Hennessey, J. M. (1998). Sketching and creative discovery. Design studies, 19 (4), 519-546.

Yang, A. (2015). The drunken conversation between two cultures: Art, science and the possibility of meaningful uncertainty, Leonardo, 48 (3), 318-322.

Zahay, D., Griffin, A., \& Fredericks, E. (2004). Sources, uses, and forms of data in the new product development process. Industrial Marketing Management, 33(7), 657-666. 